\title{
АНАЛИЗ ОБЕСПЕЧЕННОСТИ ГОРОДА НОВОСИБИРСКА ОЗЕЛЕНЕННЫМИ ТЕРРИТОРИЯМИ ОБЩЕГО ПОЛЬЗОВАНИЯ
}

\section{Людмила Владимировна Калинченко}

Сибирский государственный университет геосистем и технологий, 630108, Россия, г. Новосибирск, ул. Плахотного, 10, обучающийся, тел. (996)071-79-20, e-mail: 1k090299@mail.ru

\section{Анатолий Викторович Ерщов}

Сибирский государственный университет геосистем и технологий, 630108, Россия, г. Новосибирск, ул. Плахотного, 10, кандидат технических наук, доцент кафедры кадастра и территориального планирования, тел. (383)361-01-09, e-mail: er-tos@inbox.ru

В статье описан алгоритм анализа обеспеченности города Новосибирск озелененными территориями общего пользования с помощью программного комплекса MapInfo. На примере двух районов проведен полный анализ по количеству рекреационных зон города Новосибирск и было выявлено, что общий показатель города еще не означает, что во всех районах соблюдена норма по общей площади озеленения.

Ключевые слова: анализ обеспеченности озелененными территориями общего пользования, рекреационная зона, озеленение

\section{SECURITY ANALYSIS OF THE CITY OF NOVOSIBIRSK WITH GREEN AREAS OF GENERAL USE}

\section{Lyudmila $V$. Kalinchenko}

Siberian State University of Geosystems and Technologies, 10, Plakhotnogo St., Novosibirsk, 630108, Russia, Student, phone: (996)071-79-20, e-mail: 1k090299@mail.ru

\section{Anatoly V. Ershov}

Siberian State University of Geosystems and Technologies, 10, Plakhotnogo St., Novosibirsk, 630108, Russia, Ph. D., Associate Professor, Department of Cadastre and Territorial Planning, phone: (961)845-44-09, e-mail: er-tos@inbox.ru

The article describes an algorithm for security analysis of the city of Novosibirsk with green areas of common use using the MapInfo software package. On the example of two districts, a complete analysis was carried out on the number of recreational zones in the city of Novosibirsk and it was found that the general indicator of the city does not mean that in all districts the norm for the total area of greening was observed.

Keywords: security analysis of green areas of common use, recreational zone, landscaping

Озеленению и состоянию рекреационных зон посвящено много исследований. Санитарно-гигиенические, экологические и эстетические функции зеленых насаждений имеют большое значение для населения города. В озеленении городов формируются новые подходы, ориентированные на эстетическое разнообразие. Основными центрами сохранения природной среды являются рощи, парки, 
сады и лесопарки. Сохранение рекреационной зоны по существу является единственным способом поддержания в городах необходимого уровня разнообразия флоры и фауны [1]. Следовательно, озеленение любого города является актуальной задачей городских властей. Рассмотрим состояние рекреационной зоны города Новосибирск, сравнивая ее действительное состояние с нормами озеленения для крупнейших городов.

Для начала ознакомимся с определением озеленения и его нормативами.

Под озелененной территорией общего пользования понимается озелененная территория, предназначенная для различных форм отдыха, к ней относятся лесопарки, сады, скверы, бульвары и городские леса.

Норма озеленения - это площадь озелененных территорий общего пользования, приходящихся на одного жителя. Суммарная площадь озеленения вычисляется отношением общей площади города на общее количество населения города [2].

Суммарная площадь озелененных территорий общего пользования таких как, парки, лесопарки, скверы и т.д. должна быть не менее данных из таблицы [3].

Нормы озеленения для разных видов городов

\begin{tabular}{|c|c|}
\hline Вид города & Норма озеленения, $\mathrm{M}^{2} /$ чел. \\
\hline $\begin{array}{c}\text { Для крупнейших, крупных } \\
\text { и больших (от } 100 \text { тыс. чел.) }\end{array}$ & 16 \\
\hline $\begin{array}{c}\text { Для средних (от } 50 \text { до } 100 \\
\text { тыс. чел.) }\end{array}$ & 8 \\
\hline Для малых (до 50 тыс. чел.) & 13 \\
\hline
\end{tabular}

Для выполнения анализа обеспеченности города Новосибирск озелененными территориями общего пользования была выполнена оцифровка рекреационной зоны по данным космической съемки, также были использованы территориальные зоны из ЕГРН (рис. 1).

C помощью команды SQL-запроса программного комплекса MapInfo была вычислена сумма площадей всех рекреационных зон города Новосибирск, которая составила 109825 957,65 м². Население Новосибирска на 2020 год составляет 1625631 человек, следовательно, город относится к крупнейшим и для него суммарная площадь рекреационных зон должна быть не меньше $16 \mathrm{~m}^{2} /$ чел [4]. По полученным данным посчитана суммарная площадь озелененных территорий общего пользования, равная 67,9 м² $^{2}$ чел., что больше $16 \mathrm{~m}^{2} /$ чел.

Таким образом анализ показывает, что в Новосибирске сумма площадей озелененных территорий общего пользования соответствует нормам и даже превышает в несколько раз. 


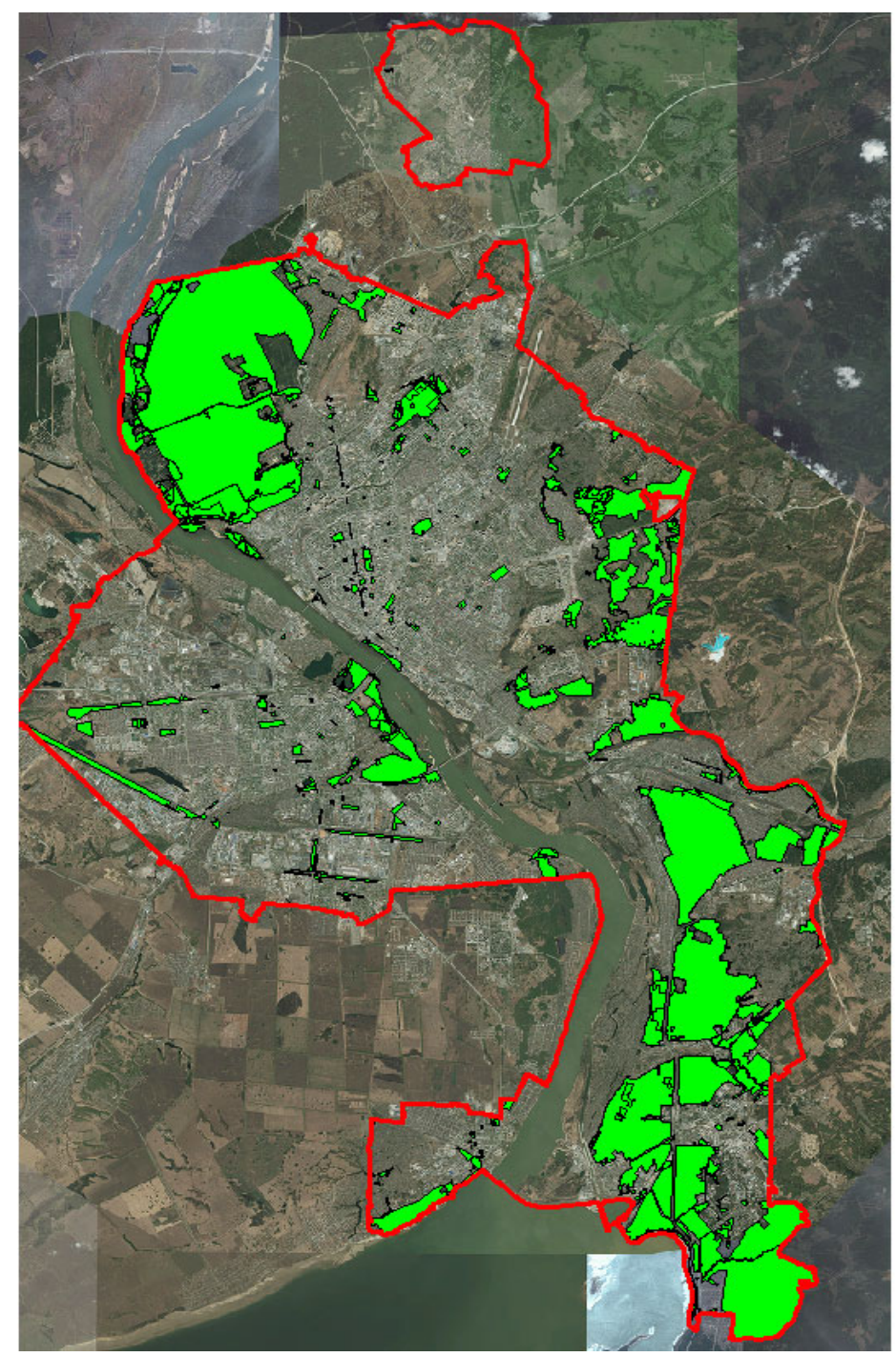

Рис. 1. Рекреационная зона в границах Новосибирска

Однако при подробном рассмотрении расположения рекреационных зон по отдельным районам Новосибирска заметно, что зеленая зона преобладает в Заельцовском районе, а если же посмотреть в другие районы, такие как Ленинский, Кировский и Железнодорожный можно заметить, что зон озеленения практически нет (рис. 2 и 3 ).

Поэтому на этом этапе анализ не был закончен. Дальнейшее исследование на предмет обеспеченности озелененными территориями коснулось Ленинского района города Новосибирск. Аналогично предыдущему запросу была вычислена площадь рекреационных зон - 2979751,55 м² $^{2}$ население района составляет 308869 человек. Следовательно, сумма площадей озелененных территорий ленинского района равна 9,7 м²/чел., что меньше нормы.

Для того чтобы убедиться, что сумма площадей озелененных территорий города Новосибирск больше нормы из-за Заельцовского района был проведен анализ и для него. Площадь зон озеленения района 36692754,82 м² $^{2}$, население района 146306 человек. Соответственно сумма площадей озелененных территорий ленинского района равна 250,8 м²/чел., что в несколько раз превышает норму. 


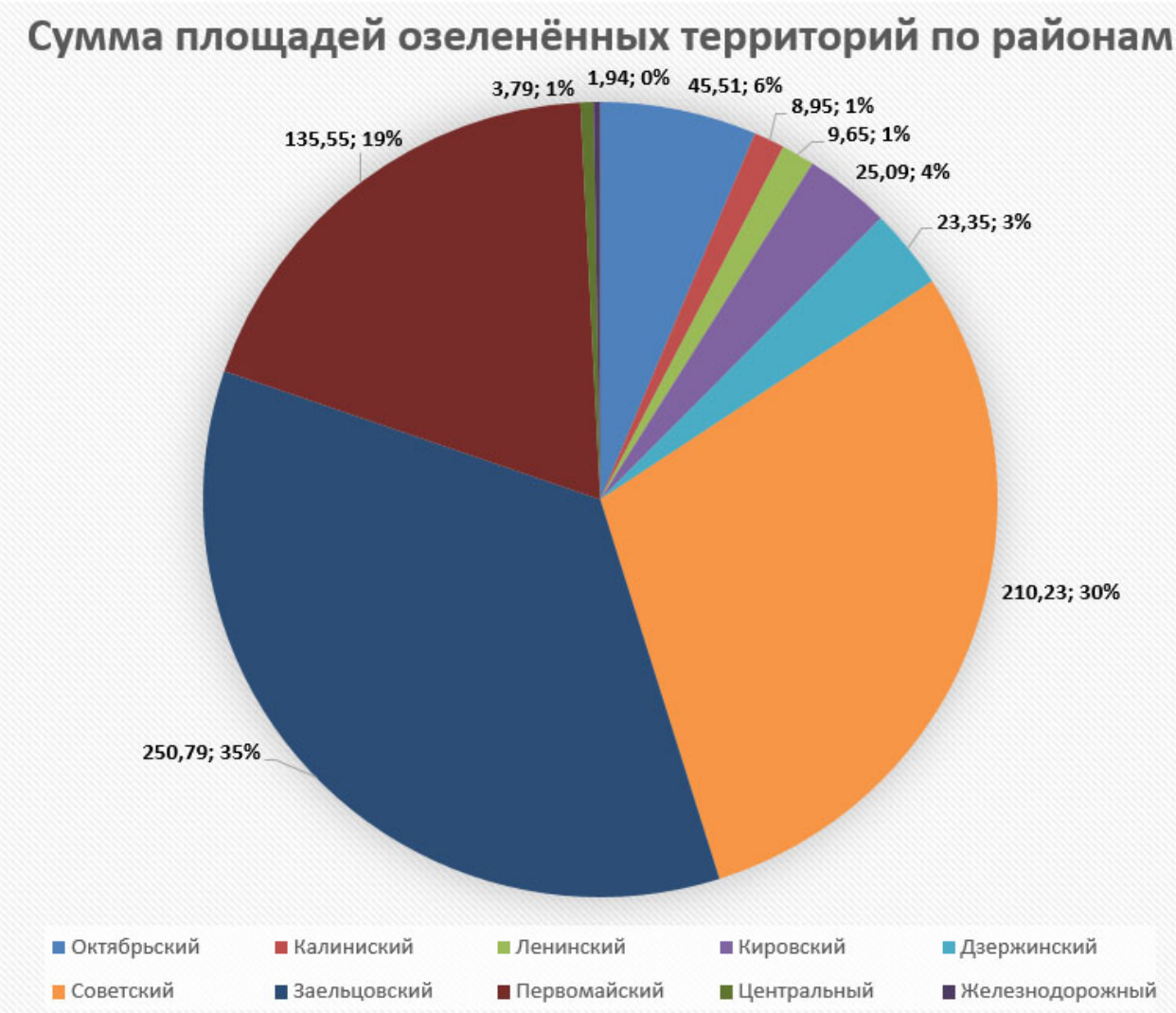

Рис. 2. Сумма площадей озелененных территорий по районам Новосибирска

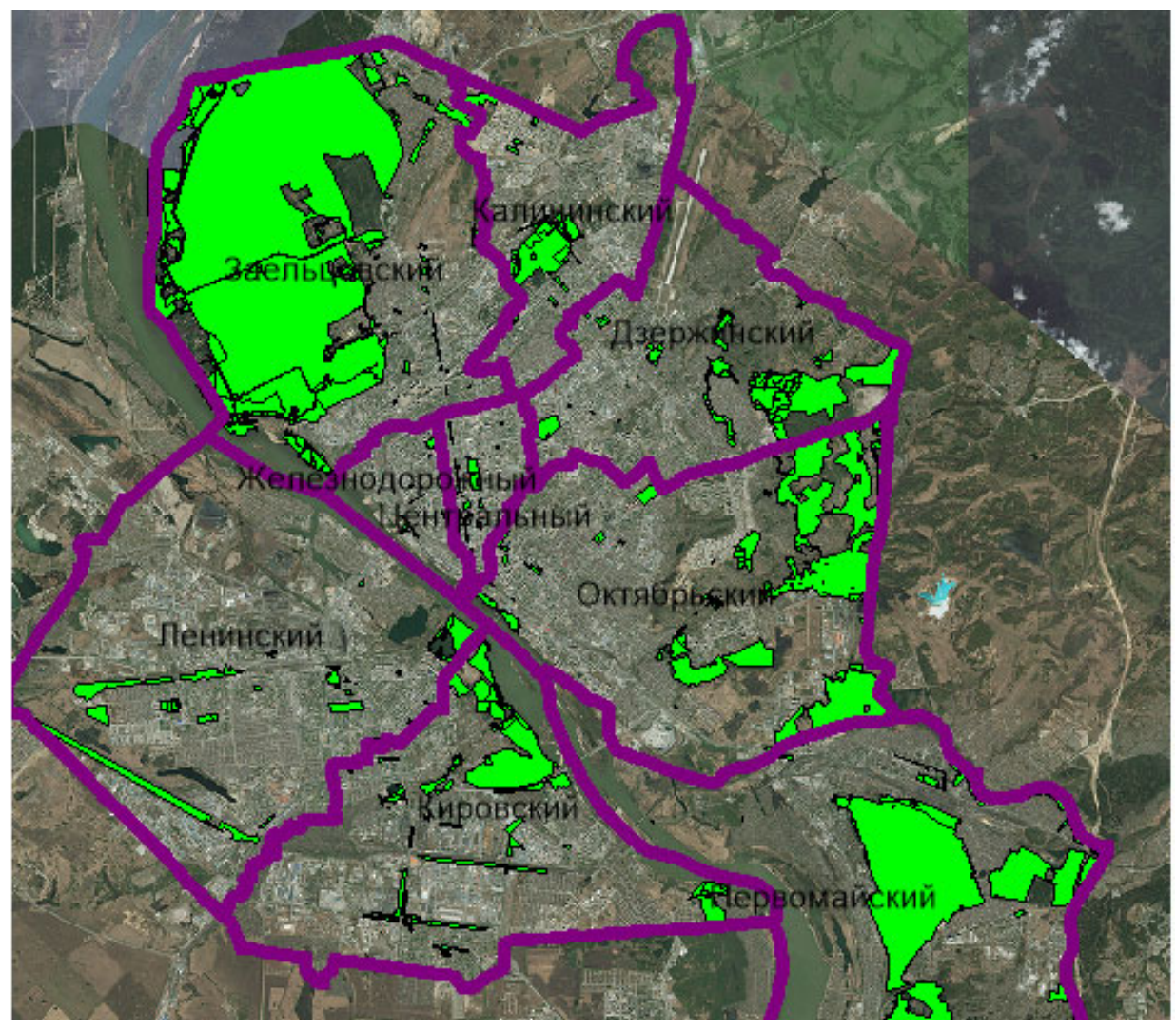

Рис. 3. Рекреационная зона в границах районов Новосибирска 
В процессе анализа обеспеченности города Новосибирск озелененными территориями общего пользования было выявлено, что несмотря на то что город переходит далеко за порог нормы в отдельных районах есть над чем поработать. В Ленинском районе наблюдается нехватка зеленых насаждений, в связи с чем населению этого района для прогулок недостает парков, скверов или садов вблизи дома. А Заельцовский же район наоборот является образцовопоказательным не только для других районов Новосибирская, но и для всех городов России $[5,6]$.

\section{БИБЛИОГРАФИЧЕСКИЙ СПИСОК}

1. Градостроительство. Планировка и застройка городских и сельских поселений $\mathrm{CH}$ PК3.01-01-2013 [Электронный ресурс] - Режим доступа: URL: https://cadlancer.com/market/lib/norm_kz/градостроительство-планировка-и-застройка-городских-и-сельских-населенных-пунктов-СН-РК-301-01-2013 - Загл. с экрана.

2. Дубровский А. В., Подрядчикова Е. Д., К вопросу рекреационно - туристического землепользования в сельской местности [Текст] / В сборнике: Информационные технологии, системы и приборы в АПК Материалы 5-й Международной научно-практической конференции. Краснообск: СИБФТИ. - 2012. С. 436-440.

3. Дубровский А. В., Подрядчикова Е. Д., Геоинформационные аспекты формирования рекреационного кадастра [Текст] / Интерэкспо Гео-Сибирь. 2013. Т. 3.№3. - Новосибирск: СГГА. - С. 103-109.

4. Рекреационное пространство как объект управления инновационным развитием территорий города [Электронный ресурс] - Режим доступа: https://cyberleninka.ru/article/n/rekreatsionnoeprostranstvo-kak-obekt-upravleniya-innovatsionnym-razvitiem-territoriy-goroda - Загл. с экрана.

5. Рекреация [Электронный ресурс]. - Режим доступа: https://www.booksite.ru/fulltext/1/001/008/096/348.htm - Загл. с экрана.

6. Роль рекреации в освоении пространства [Электронный ресурс] - Режим доступа: https://cyberleninka.ru/article/n/rol-rekreatsii-v-osvoenii-prostranstva - Загл. с экрана.

7. Рекреационные ресурсы и системы Земли [Электронный ресурс] - Режим доступа:https://www.sgu.ru/sites/default/files/education/programs/2017/03/rekreacionnye_resursy_i_ sistemy_zemli.pdf - Загл. с экрана.

(C) Л. В. Калинченко, А. В. Ершов, 2021 